\title{
Interaction of Retinol with HSA using Spectroscopic Techniques
}

\author{
H. Alsamamra ${ }^{1}$, R. Drabee ${ }^{2}$, S. Abu-Sharkh ${ }^{3}$, S. Darwish ${ }^{4}$, M. Abu $\quad$ Teir $^{5}$ \\ Department of Physics, Al-Quds University, Palestine
}

\begin{abstract}
The interaction between retinol and HSA has been investigated using UV-absorption spectrophotometry, fluorescence spectroscopy and Fourier Transform Infrared (FT-IR) spectroscopy.UV-absorption spectrophotometry showed an increase in the absorption intensity with increasing the molecular ratios of retinol to HSA, it is found that the value of the binding constant is estimated to be $1.7176 \times 10^{2} M^{-1}$. FTIR spectroscopy is used in the mid infrared region with Fourier self deconvolution, second derivative, difference spectra, peak picking and curve fitting were used to determine the effect of Retinol on the protein secondary structure in the amides I, II and Ill regions. Analysis of FTIR absorbance spectra is found that the intensity of the absorption bands increased with increasing the molecular ratios of retinol, however from the deconvoluted and curve fitted spectra found that the absorbance intensity for a-helix decreases relative to $\beta$-sheets, this decrease in intensity is related to the formation of $\mathrm{H}$-bonding in the complex molecules.
\end{abstract}

\section{Introduction}

Retinol known as Vitamin $\mathrm{A}_{1}$ (Fig. 1)is essential throughout life as it is required in reproduction, embryonic, vision, growth, differentiationof epithelial cells and tissue maintenance (Peng et al., 2008). Vitamin A covers the retinoids; a group of lipid-soluble compounds which have similar physiological functions and metabolic activities: retinol, retinaland retinoic acid(Serkdyuk et al., 2007). Retinol is used toprevent vitamin A deficiency, especially that which is resulting in xerophthalmia.

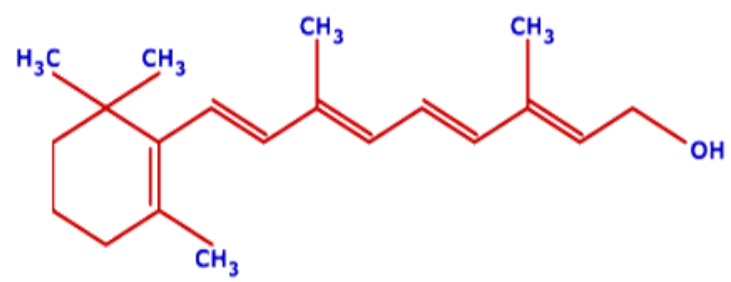

Figure 1: Chemical structure of Retinol

Human serum albumin (HAS) is the most abundant protein in blood plasma and is able to bind and thereby transport various compounds such as fatty acids, hormones, bilirubin, tryptophan, steroids, metal ions, therapeutic agents and a large number of drugs (Darwish et al. 2010). HSA serves as the major soluble protein constituent of the circulatory system, it contributes to colloid osmotic blood pressure, it can bind and carry drugs which are poorly soluble in water (Abu Teir et al., 2010). HSA concentration in humanplasma is $40 \mathrm{mg} / \mathrm{ml}$ (Tusharet al. 2008). It is a globular protein consisting of a single peptide chain of 585 amino acids. This protein composed of three structurally similar domains (labeled as I, II, III)(Cui et al. 2008). Each containing two sub domains (A \& B) having six and four $\alpha$-helices, respectively. The molecular interactions between HSA and some compounds have been investigated successfully (Ouameuret al. 2004; Abu Teiretal. 2010; Abu Teiret al. 2014; Darwishet al. 2010). It has recently been proved that serum albumin plays a decisive role in the transport and disposition of variety of endogenous and exogenous compound such as fatty acids, hormones, bilirubin, drugs.
Infrared spectroscopy provides measurements of molecularvibrations due to the specific absorption of infrared radiation by chemical bonds. It is known that the form and frequency of the Amide I band, which is assigned to the $\mathrm{C}=\mathrm{O}$ stretching vibration within the peptide bonds is very characteristic for the structure of the studied protein (Jiang et al. 2004). From the band secondary structure, components peaks (a-helix, b-strand) can be derived and the analysis of this single band allows elucidation of conformational changes with high sensitivity.

This work will be limited to the mid-range infrared, which coversthe frequency range from 4000 to $400 \mathrm{~cm}^{-1}$. This wavelength region includes bands that arise from three conformational sensitive vibrations within the peptide backbone (Amides I, II and III) of these vibrations, Amide I is the most widely used and can provide information on secondary structure composition and structural stability. One of the advantages of infrared spectroscopy is that it can be used with proteins that are either in solution or in thin films. In addition, there is a growing body of literature on the use of infrared to follow reaction kinetics and ligand binding in proteins, as well as a number of infrared studies on protein dynamics.

Other spectroscopy techniques are usually used in studying theinteraction of retinol and protein, fluorescence and UV spectroscopy are commonly used because of their high sensitivity, rapidity and ease of implementation. The binding mode of retinol to HSA was investigated by means of UVabsorption spectroscopy, Fluorescence spectroscopy, and FTIR spectroscopy. Spectroscopic evidence regarding the retinol binding mode, retinol binding constant and the effects of retinol on the protein secondary structure are provided here.

\section{Material and Methods}

HSA (fatty acid free), Retinol (Vitamin $A_{1}$ ) were purchased from Sigma Aldrich chemical company and used without further purifications. The data were collected using samples in the form of thin films for FT-IR measurements and liquid form for UV-VIS 


\section{International Journal of Science and Research (IJSR) \\ ISSN (Online): 2319-7064}

Index Copernicus Value (2016): 79.57 | Impact Factor (2015): 6.391

\subsection{Preparation of stock solutions}

HSA was dissolved in $25 \%$ ethanol in phosphate buffer Saline and at physiological ( $\mathrm{pH}$ 6.9- 7.4), to a concentration of $(80 \mathrm{mg} / \mathrm{ml})$, and used at final concentration of $(40 \mathrm{mg} / \mathrm{ml})$ in the final vitamin- HSA solution. Retinol with molecular weight of (430.71 g.mol ${ }^{-1}$ ), was dissolved in $25 \%$ ethanol in phosphate buffer Saline and, then the solution was placed in ultrasonic water path (SIBATA AU-3T) for two days to ensure that all the amount of Retinol was completely dissolved. The final HSA-Retinol solutions was decreased such that the molecular ratios (HSA:retinol) are 1:20, 1:10, $1: 5,1: 2$, and 1:1. All samples were made by mixing equal volume from $\mathrm{HSA}$ to equal volume from different concentrations of retinol. The solution of HAS and retinol were incubated for $1 \mathrm{~h}$ (at $\left.20{ }^{\circ} \mathrm{C}\right)$.

\subsection{UV-absorption spectra}

The absorption spectra were obtained by the use of a NanoDropND-100 spectrophotometer. The absorption spectra were recorded for free HSA $(40 \mathrm{mg} / \mathrm{ml})$ and for its complexes with retinol solutions with the different ratios. Repeated measurements were done for all the samples.

\subsection{Fluorescence}

The fluorescence measurements were performed by a NanoDrop_ ND-3300 Fluorospectrometer at 25_C. The excitation source comes from one of three solid-state light emitting diodes (LED's). The excitation source options include: UV LED with maximum excitation $365 \mathrm{~nm}$, Blue LED with excitation $470 \mathrm{~nm}$, and white LED from 500 to $650 \mathrm{~nm}$ excitation. A 2048-element CCD array detector covering 400-750 nm, is connected by an optical fiber to the optical measurement surface.

\subsection{FT-IR spectroscopy}

The FT-IR measurements were obtained on a Bruker IFS 66/Sspectrophotometer equipped with a liquid nitrogencooled MCT detector and a $\mathrm{KBr}$ beam splitter. The spectrometer was continuously purged with dry air during the measurements. Samples are prepared after $2 \mathrm{~h}$ of incubation of HSA with retinol solution at room temperature, five drops of the serum sample were placedon a certain area on a silicon window plate and left to dry at roomtemperature. The dehydrated films on one side of a silicon window plate of the samples containing different ratios of retinol with the same protein content. The absorption spectra were obtained in the wave number range of $400-4000 \mathrm{~cm}^{-1}$. A spectrum was taken as an average of 60 scans to increase the signal to noise ratio, and the spectral resolution was at $4 \mathrm{~cm}^{-1}$. The aperture used in this study was $8 \mathrm{~mm}$, since we found that this aperture gives best signal to noise ratio. Baseline correction, normalization and peak areas calculations were performed for all the spectra by OPUS software. The peak positions were determined using the second derivative of the spectra.

\section{Results and Discussion}

\subsection{UV-absorption spectroscopy}

The excitation has been done on $210 \mathrm{~nm}$ and the absorption is recorded at $280 \mathrm{~nm}$. The UV absorbance intensity of HSA increased with the increasing of retinol concentration as shown in Fig.2. In addition, the binding of retinol to HSA resulted in a slight shift of the HSA absorption spectrum.

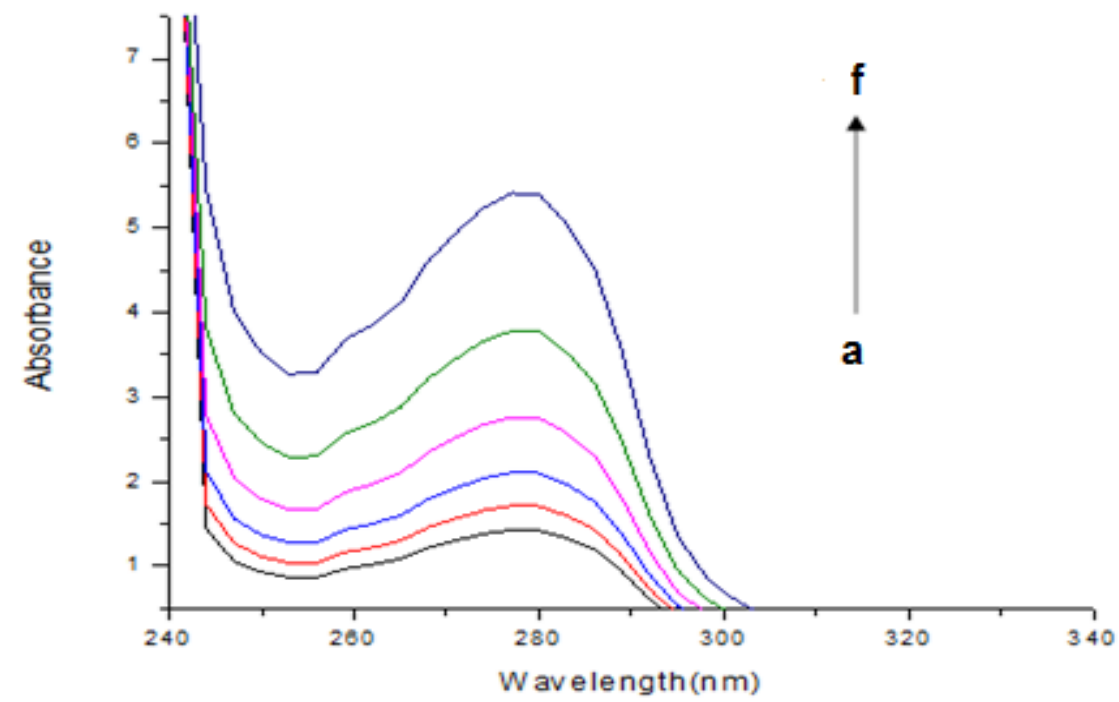

Figure 2: UV-absorbance spectra of HSA with different molar ratios of retinol, HSA: retinol $(a=1: 0, b=1: 1, c=1: 2, d=1: 5$, $\mathrm{e}=1: 10, \mathrm{f}=1: 20)$

These results clearly indicated that an interaction and some complex formation occurred between HSA and retinol separately, and also indicated that the peptide strands of protein molecules extended more upon the addition of retinol to HSA. It is evident from the spectra of the pure vitamins the little or no absorption effect which supports that the resulted peaks are due to the interaction between retinol and HSA.

The retinol - HSA complexes binding constants were determined using UV-VIS spectrophotometer (Klotz, et al., 1971; Ouameur et al., 2004), by assuming that there is only 


\title{
International Journal of Science and Research (IJSR) \\ ISSN (Online): 2319-7064
}

Index Copernicus Value (2016): 79.57 | Impact Factor (2015): 6.391

one type of interaction between retinol and HSA in aqueous solution, which leads to establish Eqs. (1) and (2) as follows:

HSA + Retinol $\leftrightarrow$ Retinol: HSA

$\mathrm{K}=[$ Retinol: HSA $] /$ [Retinol] $[\mathrm{HSA}]$

The absorption data were treated using linear double reciprocal plots based on the following equation (Lakowicz, 2006):

$$
\frac{1}{A-A_{0}}=\frac{1}{A_{\infty}-A_{0}}+\frac{1}{K\left[A_{\infty}-A_{0}\right]} \cdot \frac{1}{L}
$$

where $\mathrm{A}_{0}$ corresponds to the initial absorption of protein at $280 \mathrm{~nm}$ in the absence of ligand, $\mathrm{A}_{\infty}$ is the final absorption of the ligated protein, and $\mathrm{A}$ is the recorded absorption at different Retinol concentrations (L). The double reciprocal plot of $1 /\left(\mathrm{A}-\mathrm{A}_{0}\right)$ vs. 1/L is linear as it shown in Fig.3.

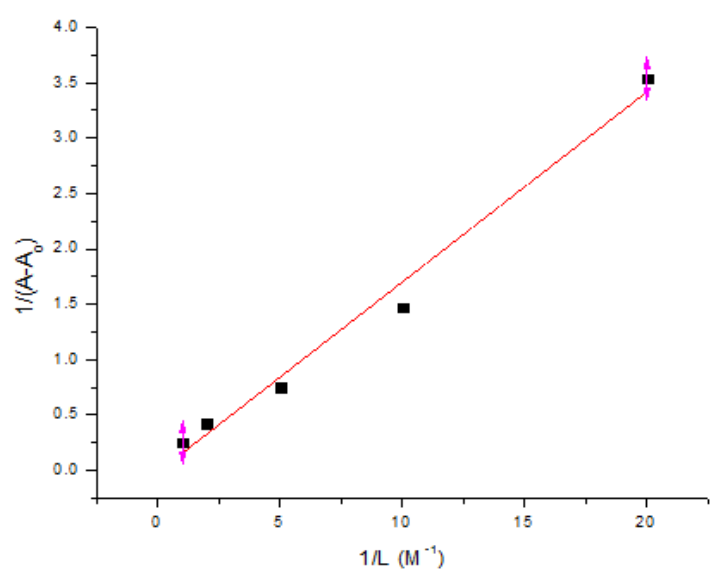

Figure 3: The plot of $1 /\left(A-A_{0}\right)$ vs. 1/L for HSA with different ratios of retinol.

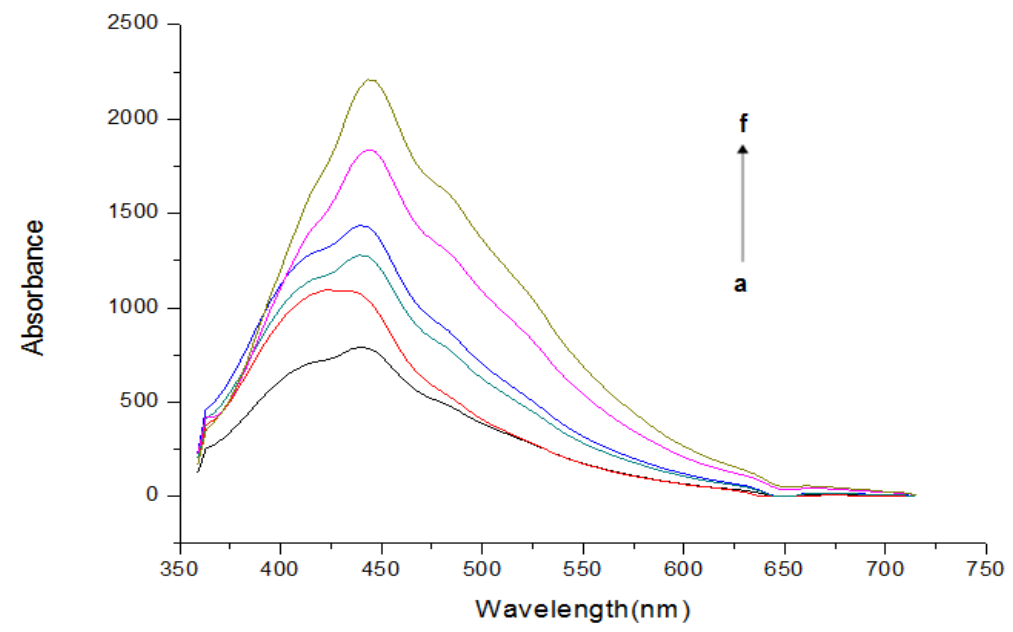

Figure 4: The fluorescence emission spectra of HSA with various ratios of Retinol $(a=1: 0, b=1: 1, c=1: 2, d=1: 5, e=1: 10$, $\mathrm{f}=1: 20$ )
Fluorescence quenching can be induced by different mechanisms that were usually classified into static quenching and dynamic quenching. Dynamic quenching arises from collisional encounters between the fluorophores and quenchers while static quenching results from the formation of a ground state complex between the fluorophores and the quenchers (Tsai, 2007).
The binding constant $(\mathrm{K})$ can be estimated from the ratio of the intercept to the slope to be $1.7176 \times 10^{2} \mathrm{M}^{-1}$ for Retinol HSA complexes, respectively. The values obtained is indicative of a weak Retinol protein interaction with respect to the other Retinol -HSA complexes with binding constants in the range of $10^{5}$ and $10^{6} \mathrm{M}^{-1}$ (Kragh- Hanse, 1981). The reason for the low stability of the Retinol -HSA complexes can be attributed to the presence of mainly hydrogen bonding interaction between protein and the Retinol polar groups or an indirect vitamin - protein interaction through water molecules (Sulkowaska et al., 2002). Similar weak interactions were observed in taxol-HSA complexes (Purcell et al. 2000).

\subsection{Fluorescence spectroscopy}

Fluorescence spectroscopy is another technique that is used widely to study binding between protein and ligand.The Fluorescence absorbance intensity of HSA increased with the increasing of retinol concentration. Various molecular interactions can decrease the fluorescence intensity of a compound such as molecular rearrangements, exited state reactions, energy transfer, ground state complex formation, and collisional quenching (Sommer, 2008). The excitation is done on $350 \mathrm{~nm}$ and emission occurs at $439 \mathrm{~nm}$. The fluorescence emission spectra of HSA with various concentrations of Retinol $(a=1: 0, b=1: 1, c=1: 2, d=1: 5$, $\mathrm{e}=1: 10, \mathrm{f}=1: 20$ ) are shown in Fig.4.
For dynamic quenching, the decrease in fluorescence intensity is described by Stern-Volmer equation (Lakowicz, 2002).

$$
\frac{F_{0}}{F}=1+K_{s v}[L]=1+k_{q} \tau_{0}[L]
$$

where $\mathrm{F}$ and $\mathrm{F}_{0}$ are the fluorescence intensities with and without quencher, $\mathrm{k}_{\mathrm{q}}$ is the quenching rate constant, $\mathrm{K}_{\mathrm{sv}}$ is the Stern-Volmer quenching constant, $(\mathrm{L})$ is the concentration of

\section{Volume 6 Issue 12, December 2017}

\author{
www.ijsr.net
}




\section{International Journal of Science and Research (IJSR) \\ ISSN (Online): 2319-7064 \\ Index Copernicus Value (2016): 79.57 | Impact Factor (2015): 6.391}

Retinol, and $\tau_{0}$ is the average lifetime of the biomolecule without quencher.

The Stern-Volmer quenching constants $K_{\mathrm{sv}}$ were obtained by finding the slope of the linear curve obtained when plotting $\frac{F o}{F}$ vs (L). The quenching rate constant $K_{\mathrm{q}}$ can be calculated using the fluorescence lifetime of HSA to be $10^{-8}$ s(Barth, 2000).

The plots of $\frac{F o}{F}$ vs [L] for HSA-Retinol complexes are shown in Fig. 5.The Stern-Volmer quenching constant for HSARetinol complexes were found to be $1.885^{*} 10^{2} \mathrm{M}$.

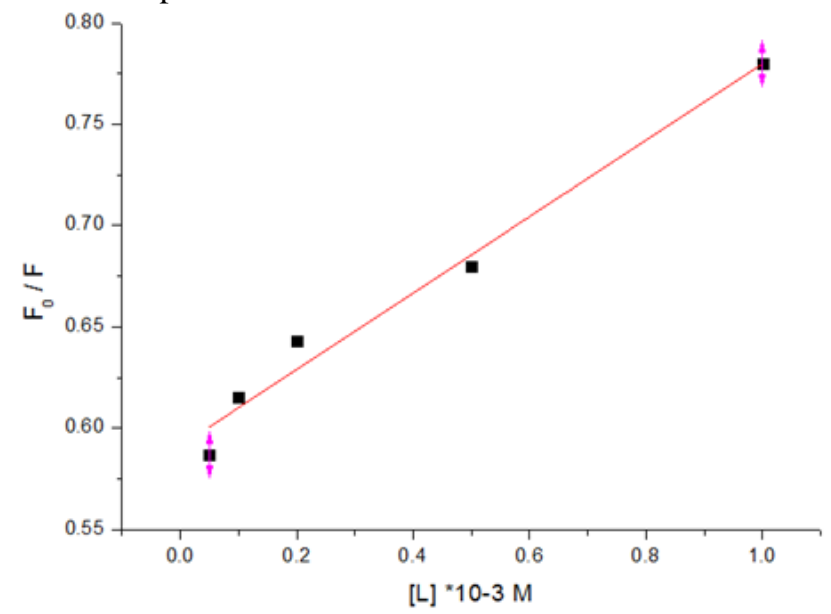

Figure 5: The plot of $\frac{F o}{F}$ vs [L] for HSA- Retinol

The quenching rate constant forHSA- Retinol were then calculated to be $1.885 * 10^{10} \mathrm{~L} \mathrm{Mol}^{-1} \mathrm{~s}^{-1}$. The obtained values of the quenching rate constants of retinol are equal the maximum dynamic quenching constants for various quenchers with biopolymers $\left(2 * 10^{10} \mathrm{~L} \mathrm{Mol}^{-1} \mathrm{~s}^{-1}\right)$ which confirms that static quenching is dominant in these complexes (Zhang et al. 2008, Darwish et al. 2012).

For static quenching, the following equation is used to determine the binding constant between HSA and retinol.

$$
\frac{1}{F_{0}-F}=\frac{1}{F_{0} K(L)}+\frac{1}{F_{0}}
$$

Where Kis the binding constant of retinol with HSA. To determine the binding constant of HSA- Retinol system, a plot of $\frac{1}{F 0-F} \mathrm{vs} \frac{1}{L}$ for different Retinol ratios is made and shown in Fig. 6. The plots are linear and have a slope of $\frac{1}{F 0 K}$ and intercept $\frac{1}{F 0}$ according to eq. (5). By taking the quotient of the intercept and the slope, the binding constants $\mathrm{K}(\mathrm{L})$ can be calculated and found to be $1.32 * 10^{2} \mathrm{M}^{-1}$ for HSA- Retinol.

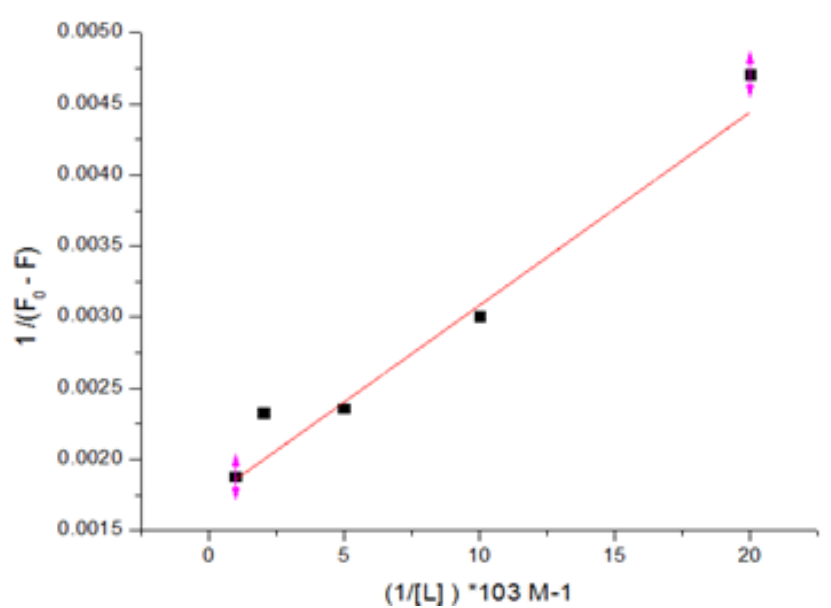

Figure 6: The plot of $\frac{1}{F 0-F}$ vs $1 / \mathrm{L}$ for HSA- Retinol complexes

\subsection{FT-IR spectroscopy}

Infrared spectra of second derivative of HSA free,where the major spectral absorbance of amide I band at $1657 \mathrm{~cm}^{-1}$ (mainly $\mathrm{C}=\mathrm{O}$ stretch ), and amide II band at $1543 \mathrm{~cm}^{-1}$ (C-N stretching coupled with $\mathrm{N}-\mathrm{H}$ bending modes) as shown in Fig. 7.

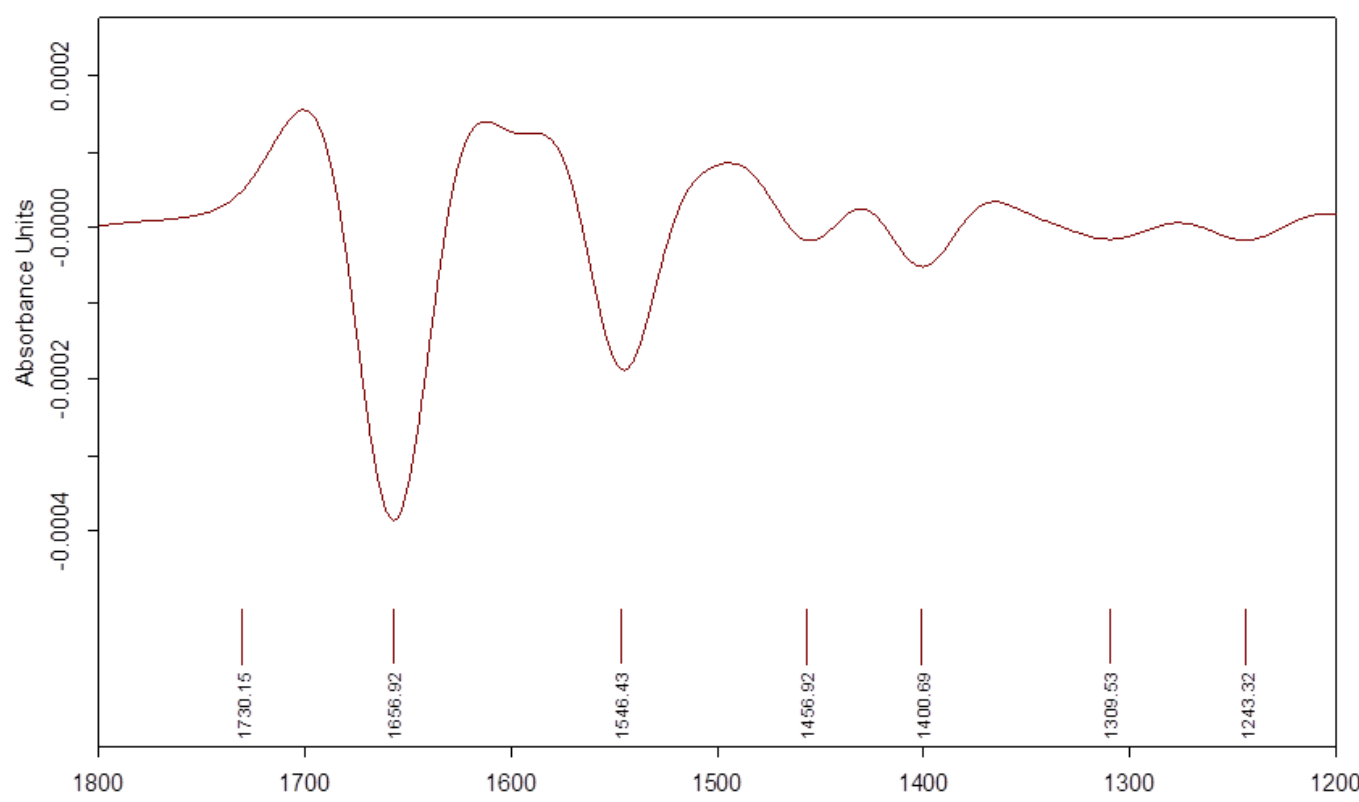

Figure 7: The spectra of HSA free (second derivative).

Volume 6 Issue 12, December 2017

www.ijsr.net

Licensed Under Creative Commons Attribution CC BY 


\section{International Journal of Science and Research (IJSR) \\ ISSN (Online): 2319-7064}

Index Copernicus Value (2016): 79.57 | Impact Factor (2015): 6.391

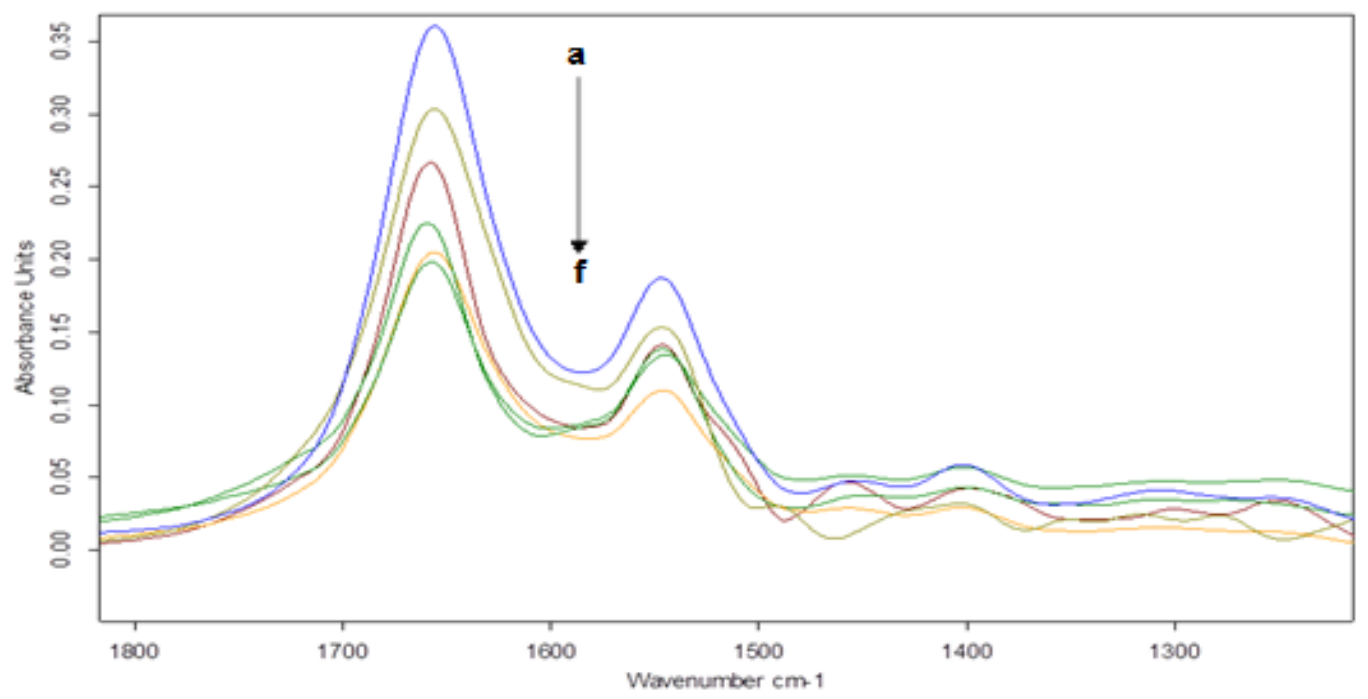

Figure 8: (a, b, c, d, e, f) Retinol -HSA with ratios (0:1, 1:1, 2:1, 5:1, 10:1, 20:1), respectively

The spectrum of HSA- Retinol mixtures with different ratios of Retinol. It is seen as the Retinol ratios is increased ,the intensity of amide I, amide II , amide III was decreased further in the spectra of all HSA- Retinol mixtures as shown in Fig. 8 . The reduction in the intensity of three amid bands is related to HSA- Retinol interactions (AbuTair et al. 2010). The peak positions of HSA with different ratios of retinol arelisted table1. For retinol -HSA interaction, it is clearly that the amide bands of HSA infrared spectrum shifted.

Table 1: Band assignment in the absorbance spectra of HSA with different Retinol molecular ratios for amide I,amide II, and amide III region

\begin{tabular}{|c|c|c|c|c|c|c|}
\hline Bands & $\begin{array}{l}\text { HSA } \\
\text { Free }\end{array}$ & $\begin{array}{c}\text { HSA- Ret. } \\
1: 01\end{array}$ & $\begin{array}{c}\text { HSA- Ret. } \\
1: 02\end{array}$ & $\begin{array}{c}\text { HSA- Ret. } \\
1: 05\end{array}$ & $\begin{array}{c}\text { HSA- Ret. } \\
1: 10\end{array}$ & $\begin{array}{c}\text { HSA- Ret. } \\
1: 20\end{array}$ \\
\hline \multirow{6}{*}{$\begin{array}{c}\text { Amide I } \\
(1600-1700)\end{array}$} & 1617 & & 1616 & 1619 & 1618 & 1618 \\
\hline & & & 1634 & 1634 & 1634 & 1635 \\
\hline & 1643 & 1645 & 1647 & 1646 & 1647 & 1647 \\
\hline & 1656 & 1657 & 1658 & 1658 & 1657 & 1659 \\
\hline & 1670 & 1670 & 1670 & 1669 & 1669 & 1669 \\
\hline & & & 1686 & 1686 & 1687 & 1687 \\
\hline & 1693 & 1693 & 1693 & 1693 & 1693 & 1693 \\
\hline \multirow{6}{*}{$\begin{array}{c}\text { Amide II } \\
(1480-1600)\end{array}$} & 1501 & 1501 & 1502 & 1503 & 1504 & 1503 \\
\hline & & & 1522 & 1523 & 1523 & 1522 \\
\hline & 1534 & 1537 & 1538 & 1538 & 1539 & 1538 \\
\hline & 1560 & 1560 & 1559 & 1560 & 1559 & 1559 \\
\hline & 1580 & 1580 & 1576 & 1574 & 1576 & 1576 \\
\hline & & & & 1595 & 1594 & 1594 \\
\hline \multirow{6}{*}{$\begin{array}{c}\text { Amide III } \\
(1220-1330)\end{array}$} & 1244 & 1242 & 1243 & 1243 & 1243 & 1243 \\
\hline & 1253 & 1253 & 1254 & 1254 & 1255 & 1255 \\
\hline & 1269 & 1269 & 1269 & 1268 & 1267 & 1267 \\
\hline & 1272 & 1272 & 1274 & 1276 & 1276 & 1276 \\
\hline & 1298 & 1297 & 1298 & 1298 & 1298 & 1298 \\
\hline & & & 1329 & 1328 & 1329 & 1329 \\
\hline
\end{tabular}

Inamide I band the peak positions have shifted as follows: $1617 \mathrm{~cm}^{-1}$ to $1618 \mathrm{~cm}^{-1}, 1643 \mathrm{~cm}^{-1}$ to $1647 \mathrm{~cm}^{-1}, 1656 \mathrm{~cm}^{-1}$ to $1659 \mathrm{~cm}^{-1}, 1670 \mathrm{~cm}^{-1}$ to $1669 \mathrm{~cm}^{-1}$, in addition new peaks have been appeared at high molecular ratios of retinol at $1535 \mathrm{~cm}^{-1}$ and $1587 \mathrm{~cm}^{-1}$, And the peaks at $1693 \mathrm{~cm}^{-1}$ remains unchanged after the interaction.In amide II the peak positions have shifted as follows: $1501 \mathrm{~cm}^{-1}$ to $1503 \mathrm{~cm}^{-1}$, $1534 \mathrm{~cm}^{-1}$ to $1538 \mathrm{~cm}^{-1}, 1560 \mathrm{~cm}^{-1}$ to $1559 \mathrm{~cm}^{-1}, 1580 \mathrm{~cm}^{-1}$ to $1576 \mathrm{~cm}^{-1}$, in addition new peaks have been appeared at high molecular ratios of retinol at $1522 \mathrm{~cm}^{-1}$ and $1594 \mathrm{~cm}^{-1}$. In amide III region the peak positions are also have been shifted as the following order: $1244 \mathrm{~cm}^{-1}$ to $1243 \mathrm{~cm}^{-1}, 1253$ $\mathrm{cm}^{-1}$ to $1255 \mathrm{~cm}^{-1}, 1269 \mathrm{~cm}^{-1}$ to $1267 \mathrm{~cm}^{-1}, 1272 \mathrm{~cm}^{-1}$ to
$1276 \mathrm{~cm}^{-1}$,in addition new peaks have been appeared at high molecular ratios of retinol at $1329 \mathrm{~cm}^{-1}$, And the peaks at $1298 \mathrm{~cm}^{-1}$ remains unchanged after the interaction.

Shifts in peak shape of certain elements can occur due to difference in chemical bonding, between different samples/standards. The shifts in peaks shape of HSA after the interaction with retinol has been occurred are due to the changes in protein secondary structure. Those shifts are attributed to the newly imposed hydrogen bonding between retinol (on both $=\mathrm{O}$ and $-\mathrm{OH}$ sites) and the protein (AbuTair et al., 2010;Uversky\&Permykov,2007). From Fig. 9,it has been observed that retinol-HSA complexes in amide I band

\section{Volume 6 Issue 12, December 2017}




\section{International Journal of Science and Research (IJSR) \\ ISSN (Online): 2319-7064}

Index Copernicus Value (2016): 79.57 | Impact Factor (2015): 6.391

shifts to higher frequency for the second peak 1643-1647 $\mathrm{cm}^{-1}$ and then for the major peak $1656-1659 \mathrm{~cm}^{-1}$.In amide II the higher shift occurs at the major peak 1534-1538 $\mathrm{cm}^{-1}$. The peak shift in amide III has been observed at 1272-1276 $\mathrm{cm}^{-1}$.

Hydrogen bonding may affect the bond strength, may have impact on the IR, causing the peak shift, larger or smaller. In amide I the observed characteristic band shifts often allow the assignment of these bands to peptide groups or to specific amino-acid side-chains. An additional advantage is the shift of the strong water absorbance away from the amide I region $1610-1700 \mathrm{~cm}^{-1}$ which is sensitive to protein structure. The minor but reproducible shift indicates that a partial unfolding of the protein occurs in HSA, with the retention of a residual native-like structure. It has been observed that the shifts in peaks are going toward a higher wave number, this implies that the strength of the bond has been increased but with a small percentage (Uversky\&Permykov, 2007).

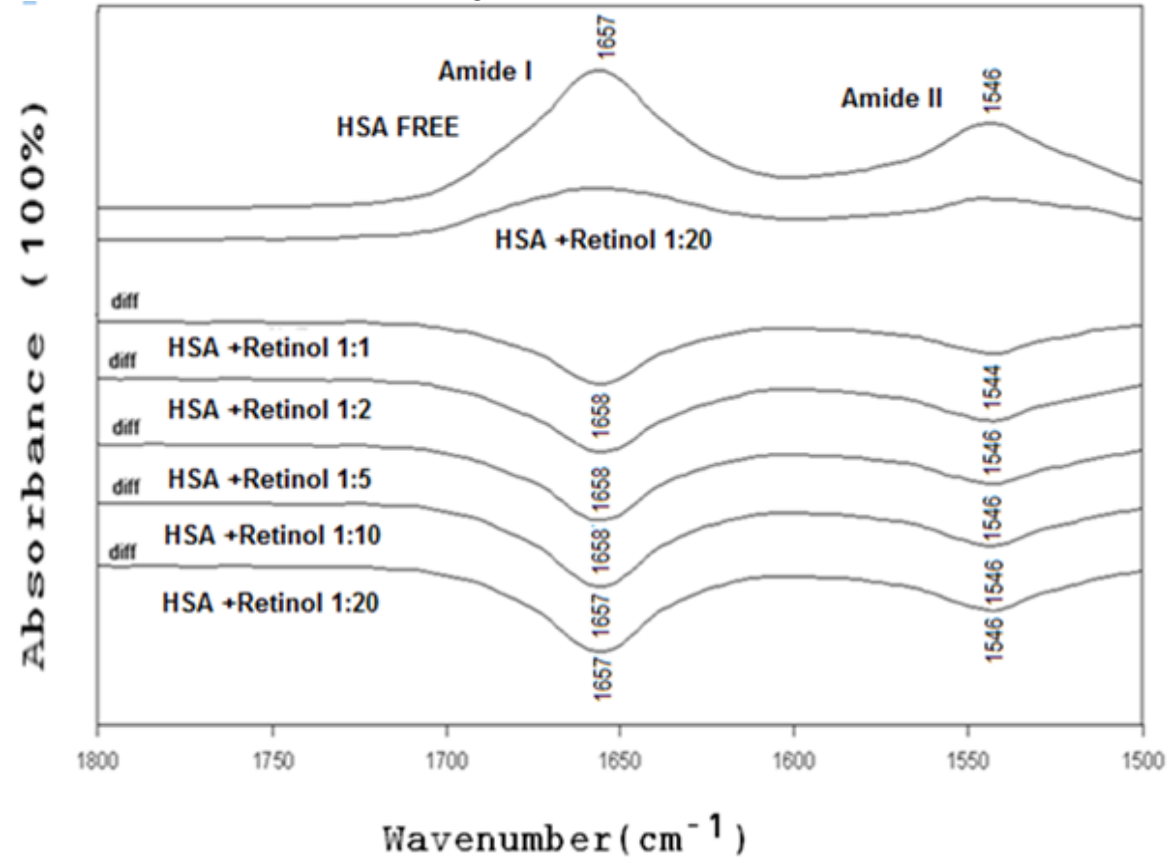

Figure 9: FTIR spectra (top two curves) and difference spectra [(protein solution+ Retinol solution)-(protein solution)] (bottom five curves) of the free human serum albumin (HSA) and its Retinol complexes in aqueous solution

The Determination of the secondary structure of HSA and its retinol complexes were carried out on the basis of the procedure described by Byler and Susi (Buxbaum, 2007). In this work a quantitative analysis of the protein secondary structure for the free HSA,andRetinol-HSA complexes in dehydrated films are determined from the shape of Amide I, II and III bands. Baseline correction was carried out in the range of $1700-1600 \mathrm{~cm}^{-1}, 1600-1480 \mathrm{~cm}^{-1}$ and $1330-1220$ $\mathrm{cm}^{-1}$ to get amide I, II, and III bands.

Then Fourier self-deconvolution and second derivative were applied to these three ranges respectively to increase spectral resolution and therefore to estimate the number, position and the area of each component bands. Based on these parameters curve-fitting process was carried out by Opus software (version 5.5) to obtain the best Lorentzian-shaped curves that fit the original HSA spectrum. The individual bands are identified with its representative secondary structure, and the content of each secondary structure of HSA is calculated by area of their respective component bands. The procedure was in general carried out considering only components detected by second derivatives and the half widths at half height (HWHH)for the component peaks are kept around $5 \mathrm{~cm}^{-1}$ (Darwish et al. 2010).

The component bands of amide I were attributed according to the well-established assignment criterion (Jiang et al.
2004; Ivanov et al. 1994). Amide I band ranging from 1610 to $1700 \mathrm{~cm}^{-1}$ generally assigned as follows $1610-1624 \mathrm{~cm}^{-1}$ are generally represented to $\beta$-sheet, $1625-1640 \mathrm{~cm}^{-1}$ to random coil, $1646-1671 \mathrm{~cm}^{-1}$ to $\alpha$-helix, $1672-1787 \mathrm{~cm}^{-1}$ to turn structure, and $1689-1700 \mathrm{~cm}^{-1}$ to $\beta$-ant parallel(Li et al. 2006; Colin, 2014). Inamide II ranging from 1480 to $1600 \mathrm{~cm}^{-1}$, the absorption band assigned in the following order: $1488-1504 \mathrm{~cm}^{-1}$ to $\beta$-sheet, $1508-1523 \mathrm{~cm}^{-1}$ to random coil, $1528-1560 \mathrm{~cm}^{-1}$ to $\alpha$-helix, $1562-1585 \mathrm{~cm}^{-1}$ to turn structure, and $1585-1598 \mathrm{~cm}^{-1}$ to $\beta$-ant parallel. For amide III ranging from 1220 to $1330 \mathrm{~cm}^{-1}$ have been assigned as follows: $1220-1256 \mathrm{~cm}^{-1}$ to $\beta$-sheet, $1257-1285 \mathrm{~cm}^{-1}$ to random coil, $1287-1301 \mathrm{~cm}^{-1}$ to turn structure, and 1302$1329 \mathrm{~cm}^{-1}$ to $\alpha$-helix(Li et al. 2009).

Most investigations have concentrated on Amide I band assuming higher sensitivity to the change of protein secondary structure (Vass et al. 1997). However, it has been reported that amide II and amide III bands have high information content and could be used for prediction of proteins secondary structure (Oberg et al. 2004; Xie et al. 2003; Jiang et al. 2004).

Based on the above assignments, the percentages of each secondary structure of HSA were calculated from the integrated areas of the component bands in Amide I, II, and III. Where the area of all the component bands assigned to a

\section{Volume 6 Issue 12, December 2017}




\section{International Journal of Science and Research (IJSR) \\ ISSN (Online): 2319-7064 \\ Index Copernicus Value (2016): 79.57 | Impact Factor (2015): 6.391}

given conformation is then summed and divided by the total area. The obtained number is taken as the proportion of the polypeptide chain in that conformation. The Secondary structure determination for the free HSA and its retinol mixture with different vitamin concentrations are given in table 2. The second derivative resolution enhancement and curve - fitted amide $I$ and secondary structure determinations of the free human serum albumin (A, B) and its retinol mixture $(C, D)$ with the highest concentrations in dehydrated films are shown in Fig.10. It is generally accepted that infrared spectra of proteins in films and in solution may display distinct differences, but these differences are due to the presence or absence of the water or buffer molecules that imprint their mark on the spectra. It has been shown that the structural information content is of the same quality in films and in solution with an (error of < $1 \%$ ) for both systems (Ahmed Ouameur et al. 2004).

Table 2: Secondary structure determination for the free HSA and its Retinol mixture for amide I, II and III.

\begin{tabular}{|c|c|c|c|c|c|c|}
\hline \multirow[t]{2}{*}{ Bands } & $\begin{array}{c}\text { HSA Free } \\
(\%)\end{array}$ & $\begin{array}{c}\text { HSA-Ret. } \\
\text { 1:1 (\%) }\end{array}$ & $\begin{array}{l}\text { HSA-Ret. } \\
1: 2(\%)\end{array}$ & $\begin{array}{c}\text { HSA-Ret. } \\
1: 5(\%)\end{array}$ & \multirow[t]{2}{*}{$\begin{array}{l}\text { HSA-Ret. } \\
\text { 1:10 (\%) }\end{array}$} & \multirow[t]{2}{*}{$\begin{array}{r}\text { HSA-Ret } \\
\mathbf{1 : 2 0}(\boldsymbol{\%})\end{array}$} \\
\hline & & \multicolumn{3}{|c|}{ Amide I } & & \\
\hline$\beta$ - sheets $\left(\mathrm{cm}^{-2}\right)$ & 16 & 19 & 14 & 18 & 19 & 24 \\
\hline \multicolumn{7}{|l|}{$(1610-1624)$} \\
\hline Random $\left(\mathrm{cm}^{-2}\right)$ & 10 & 14 & 15 & 17 & 16 & 17 \\
\hline \multicolumn{7}{|l|}{$(1625-1640)$} \\
\hline$\alpha$ - hilex $\left(\mathrm{cm}^{-2}\right)$ & 49 & 43 & 41 & 39 & 35 & 32 \\
\hline \multicolumn{7}{|l|}{$(1646-1671)$} \\
\hline Turn $\left(\mathrm{cm}^{-2}\right)$ & 14 & 11 & 13 & 11 & 13 & 11 \\
\hline \multicolumn{7}{|l|}{$(1672-1687)$} \\
\hline Anti $\beta$ - sheets $\left(\mathrm{cm}^{-2}\right)$ & 11 & 13 & 17 & 15 & 17 & 16 \\
\hline \multicolumn{7}{|l|}{$(1689-1700)$} \\
\hline & & \multicolumn{3}{|c|}{ Amide II } & & \\
\hline$\beta$ - sheets $\left(\mathrm{cm}^{-2}\right)$ & 24 & 28 & 26 & 29 & 30 & 31 \\
\hline \multicolumn{7}{|l|}{$(1488-1504)$} \\
\hline Random $\left(\mathrm{cm}^{-2}\right)$ & 10 & 13 & 15 & 13 & 12 & 13 \\
\hline \multicolumn{7}{|l|}{$(1508-1523)$} \\
\hline$\alpha-$ hilex $\left(\mathrm{cm}^{-2}\right)$ & 46 & 38 & 34 & 32 & 33 & 33 \\
\hline \multicolumn{7}{|l|}{$(1528-1560)$} \\
\hline Turn $\left(\mathrm{cm}^{-2}\right)$ & 9 & 8 & 9 & 8 & 7 & 6 \\
\hline \multicolumn{7}{|l|}{$(1562-1585)$} \\
\hline Anti $\beta$ - sheets $\left(\mathrm{cm}^{-2}\right)$ & 11 & 13 & 16 & 18 & 18 & 17 \\
\hline \multicolumn{7}{|l|}{$(1585-1598)$} \\
\hline & & \multicolumn{3}{|c|}{ Amide III } & & \\
\hline$\beta$ - sheets $\left(\mathrm{cm}^{-2}\right)$ & 32 & 37 & 35 & 38 & 39 & 38 \\
\hline$(1220-1256)$ & & & & & & \\
\hline Random $\left(\mathrm{cm}^{-2}\right)$ & 10 & 15 & 15 & 14 & 13 & 13 \\
\hline$(1257-1285)$ & & & & & & \\
\hline Turn $\left(\mathrm{cm}^{-2}\right)$ & 11 & 11 & 11 & 10 & 10 & 8 \\
\hline$(1287-1301)$ & & & & & & \\
\hline$\alpha$ - hilex $\left(\mathrm{cm}^{-2}\right)$ & 47 & 37 & 39 & 38 & 38 & 40 \\
\hline$(1302-1329)$ & & & & & & \\
\hline
\end{tabular}

In amide I region, the free HSA contained major percentages of $\alpha$-helical $49 \%, \beta$-sheet $16 \%$, random coil $10 \%$, $\beta$-turn structure $14 \%$ andanti-parallel $\beta$ - sheet $11 \%$. However, as a result of HSA-Retinol mixtureat 20:1 molecules: $\alpha$-helical structure reduced from $49 \%$ to $32 \%, \beta$-sheet increased from $16 \%$ to $24 \%$ Retinol to HAS, random coil increased from $10 \%$ to $17 \%, \beta$-turn structure reduced from $14 \%$ to $11 \%$ andantiparallel $\beta$-sheet increased from $11 \%$ to $16 \%$.

In amide II region, the free HSA contained $\alpha$-helical $46 \%, \beta$ sheet $24 \%$, random coil $10 \%, \beta$-turn structure $9 \%$ and anti $\beta$ sheet $11 \%$. As a result of HSA-Retinol mixtureat 20:1 molecules Retinol to HSA: $\alpha$-helical structure reduced from
$46 \%$ to $33 \%$, $\beta$-sheet increased from $24 \%$ to $31 \%$, random coil increased from $10 \%$ to $13 \%, \beta$-turn structure reduced from $9 \%$ to $6 \%$, and anti $\beta$-sheet increased from $11 \%$ to $17 \%$.

In amide III region, HSA free contained: $\alpha$-helical $47 \%, \beta$ sheet $32 \%$,random coil $10 \%$ and $\beta$-turn structure $11 \%$.As a result of HSA-Retinol mixtureat 20:1 molecules Retinol to HSA: $\alpha$-helical structure reduced from $47 \%$ to $40 \%, \beta$-sheet increased from $32 \%$ to $38 \%$,random coil increased from $10 \%$ to $13 \%, \beta$-turn structure decreased from $11 \%$ to $8 \%$. 
International Journal of Science and Research (IJSR)

ISSN (Online): 2319-7064

Index Copernicus Value (2016): 79.57 | Impact Factor (2015): 6.391

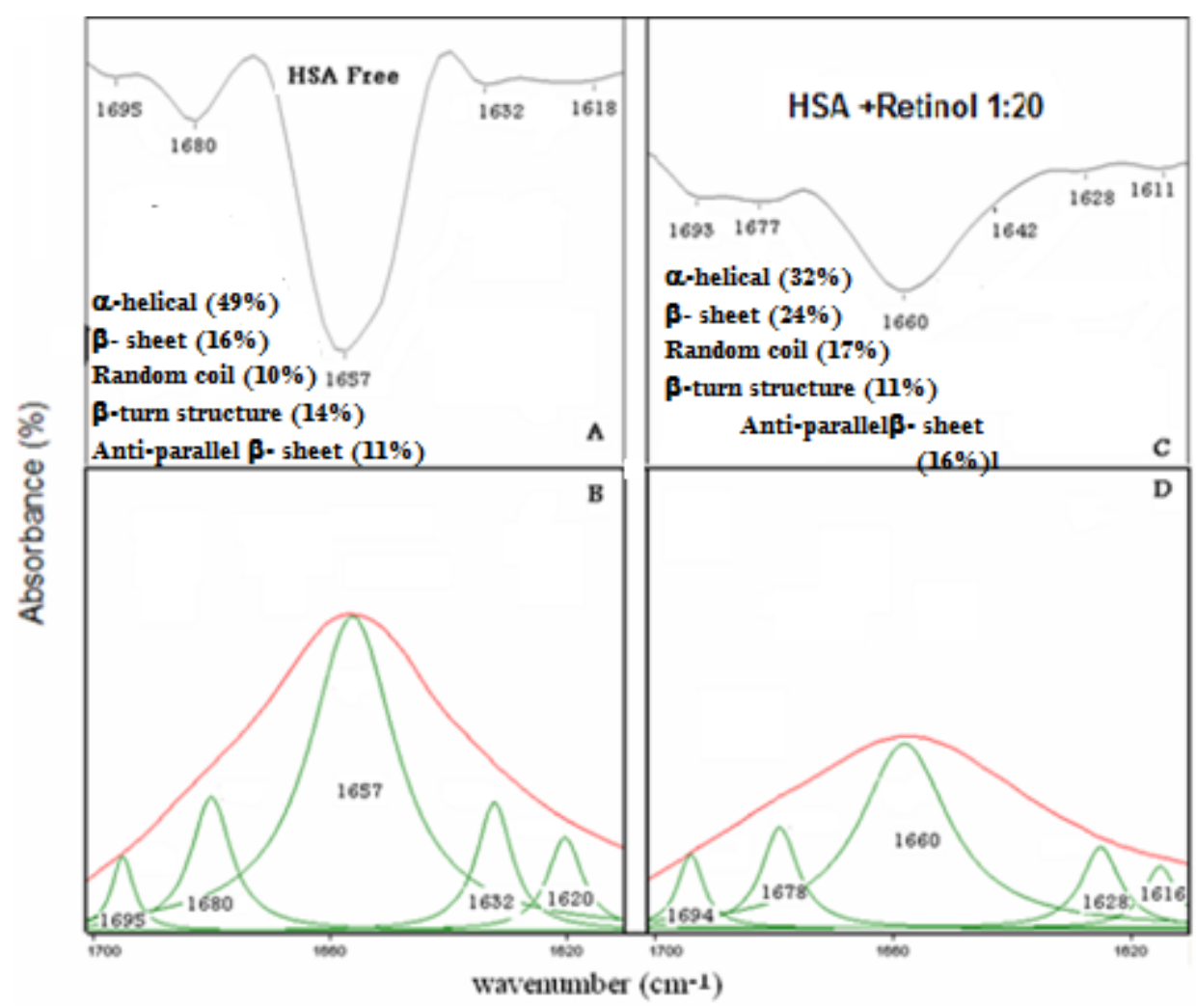

Figure 10: Second-derivative enhancement and curve-fitted Amide I region (1600-1700 cm ${ }^{-1}$ ) and secondary structure determination of the free human serum albumin ( A and B) and its Retinol mixture( C and D) with 20:Retinol: HSA ratios

The reduction of $\alpha$-helix intensity percentage in favor of the increase of $\beta$-sheets percentage are believed to be due to the unfolding of the protein in the presence of Retinol as a result of the formation of $\mathrm{H}$ bonding between HSA and the Retinol mixture. The newly formed $\mathrm{H}$-bonding result in the $\mathrm{C}-\mathrm{N}$ bond assuming partial double bond character due to a flow of electrons from the $\mathrm{C}=\mathrm{O}$ to the $\mathrm{C}-\mathrm{N}$ bond which decreases the intensity of the original vibrations (Jackson et al. 1991). It seems that the $\mathrm{H}$-bonding affects more of the original bonding in $\alpha$ - helix than in $\beta$-sheets depending on the accessibility of the solvent and on propensities of $\alpha$ - helix and $\beta$-sheets of the HSA (Parker, 1983), as discussed in chapter two the hydrogen bonds in $\alpha$-helix are formed inside the helix and parallel to the helix axis, while for $\beta$-sheet the hydrogen bonds take position in the planes of $\beta$-sheets as the preferred orientations especially in the anti-parallel sheets, so the restrictions on the formation of hydrogen bonds in $\beta$ sheet relative to the case in $\alpha$ helix explains the larger effect on reducing the intensity percentage of $\alpha$-helix to that of $\beta$ sheet (Darwish et al., 2010; Zhang et al, 1999). Similar conformational transitions from $\alpha$-helix to $\beta$-sheet structure were observed for the protein unfolding upon protonation and heat denaturation (Surewicz, et al. 1987; Holzbaur, et al. 1996). These results indicate Retinol interact with HSA through $\mathrm{C}=\mathrm{O}$ and $\mathrm{C}-\mathrm{N}$ groups in the HSA polypeptides. The Retinol-HSA mixture caused the rearrangement of the polypeptide carbonyl hydrogen bonding network and finally the reduction of the protein $\alpha$-helical structure.

In summary, the binding of retinol to HSA has beeninvestigated by UV-absorption spectroscopy, fluorescence spectroscopy and by FT-IR spectroscopy. From the UV and Fluorescence Investigations, we determined values for the binding constant and the quenching constant. The experimental results indicates a low binding affinity between retinol with HSA. Analysis of FT-IR spectrum indicated that increasing the concentration of Retinol lead to the unfolding of protein, decreasing the percentage of the $\alpha$ helical structure in favor of $\beta$-sheet structure. Beside that it can be inferred that the binding forces which are involved in the binding process includes hydrophobic interactions. The newly formed $\mathrm{H}$-bonding result in the $\mathrm{C}-\mathrm{N}$ bond assuming partial double bond character due to a flow of electrons from the $\mathrm{C}=\mathrm{O}$ to the $\mathrm{C}-\mathrm{N}$ bond which decreases the intensity of the original vibrations.

\section{References}

[1] Abu Tair, M., Ghithan s, J., Darwish , M., Abuhadid, M. (2010). Journal of Applied Biological Sciences 5 (13): p:35-47.

[2] Abu Teir M. M., Ghithan J., Abu-Taha M. I.1, Darwish S. M., Abu-hadid M. M. (2014). Journal of Biophysics and Structural Biology. 6(1).1-12.

[3] Abu Teir,M.M., Ghithan,J., Darwich,S., Abu-hadid, M.M. (2012). Journal of Applied Biological Science. 6 (3), P45-55.

[4] Ahmed Quamour, A. (2004). Biopolymers, 73, p503.

[5] Barth, A. (2000). The infrared absorption of amino acid side chains. Progress in Biophysics \& Molecular Biology. P:141-173.

[6] Buxbaum, E. (2007). Fundamentals of protein structure and function, Springer Science \& Business media, LLC.

[7] Colin, D. (2014). Introduction to Protein Structure Prediction. www.biostst.wisc.edu/bmi776/

\section{Volume 6 Issue 12, December 2017}




\section{International Journal of Science and Research (IJSR) \\ ISSN (Online): 2319-7064 \\ Index Copernicus Value (2016): 79.57 | Impact Factor (2015): 6.391}

[8] Cui,A., Lixia Qin, A., Guisheng, Z.A., Xiaobing, L.A., Xiaojun,Y.B., Beilei ,L.B (2008). Bioorganic \& Medicinal Chemistry,16,7615-7621.

[9] Darwish, S., Abu sharkh, S., Abu Teir, M., Makharza, S., Abu-hadid, M. (2010). Journal of Molecular Structure, 963, p122.

[10] Darwish, S.M., Abu Teir M. M., Abu-hadid, M.M. (2012). journal of spectroscopy.

[11] Holzbaur, I., English, A., Ismail, A.(1996). Biochemistry 35, p5488.

[12]Ivanov, A. et al. (1994). Journal of Applied Spectroscopy, 60, p305.

[13] Jackson, M., and Mantsch, H. (1991). J. Chem., 69, p1639.

[14] Jiang, M., Xie, M., Zheng, D., Liu, Y., Li, X., Chen, X., (2004). Journal of Molecular Structure, 692, p71.

[15] Klotz, M., and Hunston,L., (1971). Biochemistry, 10, p3065.

[16] Kragh-Hansen, U. (1981). Pharmacol. Rev., 33, p17.

[17]Lakowicz, J. (2006): Principles of Fluorescence Spectroscopy, $3^{\text {rd }}$ ed, Springer Science+Business Media, USA.

[18] Lakowicz, J.R. (2002). Topics in fluorescence spectroscopy, Vol 5, Kluwer academic publishers.

[19]Li, Y., He, W., Dong, Y., Sheng, F., Hu, Z. (2006). Bioorganic \& Medicinal Chemistry, 14, p1431.

[20]Li,Y., Ying, He,W., Ming, D., Shenga, F., Zhi,D.(2009). Bioorganic \& Medicinal Chemistry,14,P 1431-1436.

[21] Oberg, K., Ruysschaert, J., Goormaghtigh, E. (2004). Eur. J. Biochem., 271, p2937.

[22] Ouameur, A., Mangier, E., Diamantoglou1, S., Carpentier, R., Tajmir-Riahi, A., (2004). Biopolymers, 73, p503.

[23] Ouameur,A., Mangier,S., Diamantoglou, R., Rouillon, R., CarpentierH. A., Tajmir, R.. (2004). Biopolymers, Vol. 73, 503-509

[24] Peng, L., Minboa, H., Fang, C., Xi, L., Chaocan, Z. (2008). Protein \& Peptide Letters, 15, p360.

[25] Purcell, M., Neault J., Tajmir-Riahi, H., (2000). BiochimicaetBiophysicaActa, 1478, p61.

[26] Serdyuk, I., Zaccai, N., Zaccai, J. (2007): Methods in Molecular Biophysics Structure, Dynamics, Function, Cambridge University Press, New York.

[27] Sommer A. (2008) Vitamin A Deficiency and Clinical Disease: An Historical Overview. J. Mol. Strurct; $138: 1835-1839$.

[28] Sulkowaska, A., (2002), J. Mol. Strurct., 614, p227.

[29] Surewicz, W., Moscarello, M., Mantsch, H. (1987). J. Biol. Chem., 262, p8598.

[30] Tsai, C., (2007). Biomacromolecules: Introduction to Structure, Function and Informatics, John Wiley \& Sons, New Jersey.

[31] Tushar,K.M., Kalyan,S.G., Anirban,S., Swagata,D., (2008). The interaction of silibinin with human serum albumin:A spectroscopic investigation. Journal of Photochemistry and Photobiology A: Chemistry 194 (297-307)

[32] Uversky, V., and Permykov, A., (2007): Methods in Protein Structure and Stability Analysis; Vibrational spectroscopy, Nova Science Publishers, Inc, Hauppauge, New York.
[33] Vass, E., Holly, S., Majer, Zs.,Samu, J., Laczko, I., Hollosi, M.(1997). Journal of Molecular Structure, 47, p408.

[34] Xie, M., and Liu, Y. (2003). Chem. J. Chin. Univ., 24, p226.

[35]Zhang, G., Que, Q., Pan, J., Guo, J. (2008). Journal of Molecular Structure, 881, p132.

Volume 6 Issue 12, December 2017

www.ijsr.net

Licensed Under Creative Commons Attribution CC BY 